\title{
EVALUATION OF PERI-IMPLANT CREVICULAR FLUID MATRIX METALLOPROTEINASE-8 LEVELS OF FLAPPED VS. FLAPLESS DENTAL IMPLANTS: A PROSPECTIVE STUDY
}

\author{
Ahmed Mohsen Mohammed Hanafy ${ }^{1 *}$
}

\begin{abstract}
Objectives: The objective of this study was to compare the placement of flapped vs. flapless dental implants utilizing clinical and immunological parameters. Subjects and methods: A total of 10 patients were received 20 dental implants. One quadrant in each patient was randomly assigned to control group while other to test group. Control group with 10 flapped implants and test group with 10 flapless implants. Follow-up examinations were carried out were performed under local after 1 week, 1 , and 3 months. All treatments anesthesia. Peri-implant sulcular fluid samples were collected as well as clinical parameters recorded at the follow up periods. Results: Peri-implant sulcus depth was significantly greater in flapped implants at both 4 and 12 postsurgical weeks $(\mathrm{P}<0.005)$. Matrix metalloproteinase- 8 values were higher to a statistically significant level in the control group at 1 $(\mathrm{P}=0.003)$ and 4 weeks $(\mathrm{P}=0.007)$ after placement. Conclusions: Matrix metalloproteinase 8 levels of peri implant crevicular fluid as well as pocket depth were decreased in flapless implants than conventional flap implant surgery.
\end{abstract}

KEYWORDS: Dental implants, flap implants, flapless implants, Matrix Metalloproteinase-8.

\section{INTRODUCTION}

Implant placement is a traumatic procedure, resulting in postoperative inflammation and bone resorption. The well-documented correlation between flap elevation and bone loss ${ }^{(1)}$ resulted in the introduction of minimally invasive or flapless techniques, an approach that is gaining popularity in implant dentistry. Flapless implant placement can be performed by minimum incision ${ }^{(2)}$, immediate perforation with the drill through the soft tissues ${ }^{(3)}$, computer guidance ${ }^{(4)}$, or soft tissue removal using a tissue punch ${ }^{(5)}$.

Flapless implantation has several advantages such as decreased surgical time, maintenance of both soft and hard tissues, decreased postoperative bleeding, faster recovery, and patient's comfort ${ }^{(6)}$.

On the other hand, significant disadvantages of flapless placement include the inability to visualize anatomic landmarks and vital structures, the potential for thermal osseous damage from the obstructed external irrigation, the inability to contour bone morphology, the increased risk of implant misplacement in relation to angulation or depth, keratinized gingival tissue loss, and the inability to manipulate soft tissues around emerging implant structures ${ }^{(7)}$.

Van de Velde T. et al ${ }^{(8)}$ analyzed deviations in position and inclination of implants placed with

1. Dentist: Ministry of Health.

-Corresponding author: ahmad.mohsin19@gmail.com

DOI: $10.21608 /$ ajdsm.2020.34680.1078 
flapless surgery compared with the ideally planned position and examined whether the outcome was affected by the experience level. The authors observed that the three-dimensional location of implants installed with flapless approach differed significantly from the ideal, although neighboring teeth were present and maximal radiographical information was available, and the outcome was not influenced by the level of experience with implant surgery.

Immunological profiling may be an alternate approach to compare flapped and flapless implants, several biomarkers detected in the gingival crevicular fluid (GCF) including various matrix metalloproteinases (MMPs) which are related to the inflammatory reaction and bone resorption ${ }^{(9)}$. More specifically, MMPs can degrade almost all extracellular matrix components and the basement membrane during both tissue repair and destruction. In periodontitis, the major collagenase detected in GCF is MMP-8 ${ }^{(10)}$, whereas in implant studies, the detection of MMP-1, $-2,-8$, and -9 was related to bone healing, remodeling, and resorption ${ }^{(11)}$.

The goal of this study was to compare the placement of flapped vs. flapless dental implants utilizing immunological and clinical parameters.

\section{SUBJECTS AND METHODS}

Study design: This study was interventional controlled clinical study. The split mouth, was carried out over a period of 3 months. A total of $10 \mathrm{pa}-$ tients were received 20 dental implants. One quadrant in each patient was randomly assigned to control group while other to test group, figure 1. Control group with 10 flapped implants and test group with 10 flapless implants. Follow-up examinations were carried out after 1 week, 1 , and 3 months. All treatments will be performed under local anesthesia.

\section{Eligibility criteria of population:}

Inclusion criteria: All subjects have to be $>18$ years of age, periodontally healthy, and partially edentulous, missing one or more teeth which were planned to be restored with fixed implant-supported restorations. Minimum buccolingual crestal bone width $>6 \mathrm{~mm}$ (based on clinical measurements and bone sounding under anesthesia), bone architecture without undercuts, and at least $4 \mathrm{~mm}$ thickness of keratinized tissues were also required. Implants were placed in extraction sites after at least 3 months of post-extraction healing.

Exclusion criteria: Subjects with systemic diseases affecting the healing process (e.g. uncontrolled diabetes mellitus) were excluded from the study. Smokers, pregnant or lactating women, individuals who used antibiotics in the last 3 months, and patients requiring guided bone regeneration for implant placement were also excluded.

Ethical consideration: Nature of the study were explained to patients; enrolled patients should sign a written consent form.

\section{Sample size}

According to the following formula for controlled clinical trial: $\mathrm{n}=(\mathrm{Za}+\mathrm{Zb})^{2} \mathrm{x}(\mathrm{S})^{2 /}(\mathrm{d})^{2}$. Where $\mathrm{S}=0.75$ and $\mathrm{d}=1$. Power analysis indicated a minimum1 8 implants ( 9 implants for each treatment modality) would be sufficient to demonstrate statistical significance at the $\mathrm{p}<0.05$ level with a power of (at least) $\geq 80 \%$.

\section{Peri-implant Crevicular Fluid Sample (PICF) Collection:}

Samples were collected at the $1^{\text {st }}$ week, 1 , and 3 months postoperatively, sampling sites were isolated with cotton rolls to prevent saliva contamination. Supragingival plaque was gently removed, and the area was dried with a gentle air stream. PICF was collected via filter papers, two filter papers were inserted $<1 \mathrm{~mm}$ into the gingival crevice to minimize tissue irritation. Samples with visible blood or plaque contamination were discarded.

PICF was treated by $1 \mathrm{ml}, 20 \mathrm{mM}$ tris- $\mathrm{HCl}$ buffer ( $\mathrm{pH}$ 6.5) in eppendorf tubes and stored at 
$-20^{\circ} \mathrm{C}$ until assay. The samples were then examined by Human Matrix Metalloproteinase- 8 specific kit of enzyme-linked immunosorbent assay (ELISA).

\section{Evaluation:}

Clinical parameters: Modified Gingival index ${ }^{(12)}$, Modified Plaque index ${ }^{(13)}$, and probing depth $^{(14)}$ were measured at 1 week, 1 , and 3 months after treatment.

Biochemical parameters The gingival crevicular fluid levels of matrix metalloproteinase- 8 (MMP-8) were analyzed by enzyme-linked immune-sorbent assay (Shanghai Sunred Biological Technology Co., China) at baseline, 1 weeks, 1 , and 3 months after treatment.

This kit used to assay the matrix metalloprotonase 8/Neutrofil collagenase (MMP-8) in the sample of the human's gingival crevicular fluid.

\section{Test principle:}

The kit uses double-antibody sandwich enzymelinked immunosorbent assay (ELISA) to assay the level of human matrix metalloproteinase 8/Neutrofil collagenase (MMP-8) in samples. Streptavidin-HRP to form immune complex; then carry out incubation and washing again to remove the uncombined enzyme.

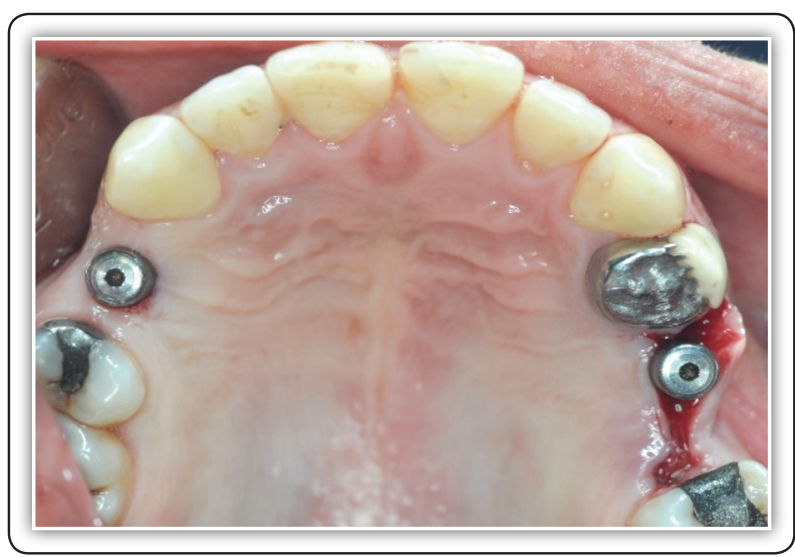

FIG (1) Healing abutments are screwed over the two implants with the two approaches.

\section{RESULTS}

\section{Clinical parameters:}

-Comparison between the two studied groups according to Modified plaque index:

At 1 week: there was a statistically significant difference in mean Modified plaque index in the two groups. Flap group showed a high Modified plaque index than Flapless group. At 1 month: there was a statistically non-significant difference in mean Modified plaque index in the two groups. At 3 months: there was a statistically significant difference in mean Modified plaque index in the two groups. Flap group showed a high Modified plaque index than Flapless group.

-Comparison between the two studied groups according to modified gingival index:

There was a statistically significant difference in mean modified gingival index in the two groups. Flap group showed a high modified gingival index than Flapless group at 1 week, $1 \& 3$ months after implant placement (Figure 2).

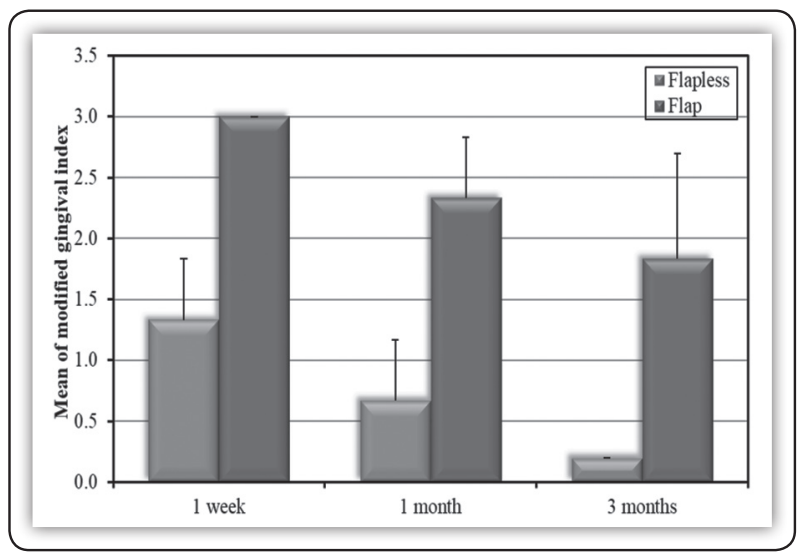

FIG (2) Comparison between the two studied groups according to modified gingival index

Comparison between the two studied groups according to Peri-implant probing depth:

There was a statistically significant difference in mean Peri-implant probing depth in the two groups. 
Flap group showed a higher Peri-implant probing depth than Flapless group at 1week, 1\&3 months after implant placement.

Immunological parameter: comparison between the two studied groups according to MMP-8

At 1 week: there was a statistically significant difference in mean MMP-8 in the two groups. Flap group showed a high MMP-8 than Flapless group. At 1 month: there was a statistically non-significant difference in mean MMP-8 in the two groups. At 3 months: there was a statistically significant difference in mean MMP-8 in the two groups. Flap group showed a high MMP-8 than Flapless group, as seen in Table (1).

TABLE (1): Comparison between the three periods in each group according to MMP-8 (ng/ml) level.

\begin{tabular}{|c|c|c|c|c|c|c|c|c|}
\hline & \multicolumn{5}{|c|}{ MMP-8 (ng/ml) level } & \multirow{2}{*}{} & \multirow{2}{*}{ F } & \multirow{2}{*}{ p } \\
\cline { 2 - 6 } & 1 week & \multicolumn{2}{|c|}{ 1 month } & \multicolumn{2}{|c|}{ 3 months } & F & \\
\cline { 2 - 6 } & Mean & \pm SD & Mean & \pm SD & Mean & \pm SD & & \\
\hline Flapless & 6.61 & 0.50 & 7.93 & 0.79 & 8.26 & 0.82 & $83.365^{*}$ & $<0.001^{*}$ \\
\hline $\mathbf{p}_{1}$ & & & \multicolumn{2}{|c|}{$<0.001^{*}$} & $<0.001^{*}$ & & \\
\hline Flap & 7.58 & 0.95 & 9.24 & 0.73 & 9.58 & 0.52 & $107.534^{*}$ & $<0.001^{*}$ \\
\hline $\mathbf{p}_{1}$ & & & \multicolumn{2}{|c|}{$<0.001^{*}$} & $<0.001^{*}$ & & \\
\hline
\end{tabular}

F: F test (ANOVA) with repeated measures, Sig. bet. periods was done using Post Hoc Test (adjusted Bonferroni) $p$ : $p$ value for comparing between the three periods $\mathrm{p} 1$ : $\mathrm{p}$ value for comparing between 1 week and each other periods

*: Statistically significant at $\mathrm{p} \leq 0.05$

\section{DISCUSSION}

The mean values of the investigated clinical parameters (mPLI, mGI and PD) were higher in the flapped compared with the flapless group at both follow-up evaluations, with statistically significant differences in PD and mGI at $1^{\text {st }}, 4^{\text {th }}$ and 12 weeks and for mPLI at 4 weeks. Between the $4^{\text {th }}$ and $12^{\text {th }}$ postoperative weeks, mPLI and mGI were reduced, with the reduction of the mPLI being statistically significant. In agreement with these findings, You et al. ${ }^{(15)}$ in an experimental study showed that the flapped group had higher GI and bleeding on probing (BOP) compared with the flapless group (GI: $0.9 \pm$ 0.5 and BOP: $0.7 \pm 0.4$ in the flapped group and zero values for both parameters in the flapless group), 3 months after implant placement.

In present study, PD was approximately $0.5-0.7$ mm higher in the flapped group, 4 and 12 weeks after implantation, and this difference was statistically significant at both time points. In a related canine study (16) also reported that the mean PD was $0.7 \mathrm{~mm}$ higher in the flapped group, 3 months postoperatively. Another interesting finding was that within the study groups, there was no statistically significant difference in mean PD values from 4 to 12 weeks, confirming that the initial maturation and stabilization of the peri-implant mucosa occurs within the first 4 weeks after implantation ${ }^{(17)}$.

A systematic review and a recent study were done by de Morais et al. and Alassiri et al. and they concluded the same and recommended use of MMP-8 as a quantitative biomarker of periodontal and peri-implant diseases adjunctive to clinical examination ${ }^{(18)}$.

In present study, we have proved the presence of MMP-8 in PISF obtained from individuals which had dental implants with both flap and flapless approaches. What is more, we have also established that the concentration of this collagenase was significantly higher in flapped than in flapless placed implants.

The immunological indicator used in this controlled clinical trial followed a similar pattern in both study groups. More specifically, MMP8 expression was stable from the 1 st to the 4 th postoperative week in both groups. However, MMP8 was expressed more intensely in the flapped group, indicating a stronger inflammatory reaction for this 
surgical approach. Thereafter, from the 4th to the 12th postsurgical week, a statistically significant decrease in MMP-8 expression was observed in both groups $(\mathrm{P}<0.001)$.

Interestingly, MMP-8 levels were similar in both implant groups on the 12 th postoperative week $(0.80$ $\pm 0.49 \mathrm{ng} / \mathrm{site} / 30 \mathrm{~s}$ for flapped implants and $0.99 \pm$ $0.49 \mathrm{ng} / \mathrm{site} / 30 \mathrm{~s}$ for flapless implants), when the initial tissue healing and osseointegration processes were completed. Statistically significant differences in the MMP-8 expression were recorded between patient groups at the 1st and 4th postoperative weeks, a finding presumably explained by the more intense bone remodeling in the flapped group as a result of the extended surgical trauma.

Choosing MMP-8 as the biomarker of special interest of our study was based on the knowledge received from numerous studies concerning its role in inflammatory cascade and its potential role as chair-side diagnostics tool of periodontal disease status around natural teeth when analyzed from oral fluids (gingival crevicular fluid, oral rinse sample, saliva) ${ }^{(19-22)}$.

For clinical use in implant patient care it would be convenient to have a test for diagnostic purposes, and interpretation of the test result if it is based on one biomarker would be practical and convenient. Collagenase-2 (MMP-8) has been found to be pathologically elevated and converted to active form in PI-affected PISF and accordingly differing from MMP-8 detected in PISF from peri-implant mucositis-affected and healthy oral implants ${ }^{(23-25)}$. These MMP-8 findings correspond to those observed in periodontitis GCF versus gingivitis and healthy GCF ${ }^{(26)}$.

We were aware when designing the study, that analyzing of one biomarker may not be diagnostically sufficient. However, MMP-8 reflects the first line of innate immune response, and based on our results MMP-8 is a potential biomarker to be used in conjunction with clinical parameters for monitoring peri-implant health and disease, MMP-8 can especially be used as an indicator of enhanced host response.

Our dento-ELISA assay utilizes an MMP-8 antibody that is selective for active form of MMP$8^{(27)}$ Active form of MMP-8 in GCF is characteristic of active periodontitis lesions, and in PISF it may also be characteristic of active PI lesions/sites ${ }^{(28)}$.

\section{CONCLUSIONS}

Matrix metalloproteinase 8 levels of peri implant crevicular fluid were decreased in flapless implants than conventional flap implant surgery. The results indicated that implants placed with a flapless approach had decreased peri-implant sulcus depth values and a milder postsurgical inflammatory reaction compared with implants placed with the conventional flap surgery.

\section{REFERENCES}

1. Kohler, C.A. \& Ramfjord, S.P. Healing of gingival mucoperiosteal flaps. Oral Surgery, Oral Medicine, and Oral Pathology (1960) 13: 89-103.

2. Jeong, S.M., Choi, B.H., Kim, J., Xuan, F., Lee, D.H., Mo, D.Y. \& Lee, C.U. A 1-year prospective clinical study of soft tissue conditions and marginal bone changes around dental implants after flapless implant surgery. Oral Surgery, Oral Medicine, Oral Pathology, Oral Radiology, and Endodontics (2011) 111: 41-46.

3. Becker, W., Goldstein, M., Becker, B.E. \& Sennerby, L. Minimally invasive flapless implant surgery: a prospective multicenter study. Clinical Implant Dentistry \& Related Research 7(Suppl.1): (2005) 1S-27S.

4. Casap, N., Tarazi, E., Wexler, A., Sonnenfeld, U. \& Lustmann, J. Intraoperative computerized navigation for flapless implant surgery and immediate loading in the edentulous mandible. The International Journal of Oral \& Maxillofacial Implants (2005) 20: 92-98.

5. Hahn, J. Single-stage, immediate loading, and flapless surgery. The Journal of Oral Implantology (2000) 26: 193-198.

6. Becker, W., Goldstein, M., Becker, B.E., Sennerby, L., Kois, D. \& Hujoel, P. Minimally invasive flapless implant placement: follow-up results from a multicenter study. Journal of Periodontology (2009) 80: 347-352. 
7. Sclar, A.G. Guidelines for flapless surgery.Journal of Oral and Maxillofacial Surgery 65(Suppl. 1) (2007): 20-32.

8. Van de Velde T, Glor F, De Bruyn H A model study on flapless implant placement by clinicians with a different experience level in implant surgery. Clin Oral Implants Res (2008) 19: 66-72.

9. Ma, J., Kitti, U., Teronen, O., Sorsa, T., Husa, V., Laine, P., Ro“nka“, H., Salo, T., Lindqvist, C. \&Konttinen, Y.T. Collagenases in different categories of peri-implant vertical bone loss. Journal of Dental Research. (2000) 79: 1870-1873.

10. Sorsa, T., Husa, V., Laine, P., Ro“nka“, H., Salo, T., Lindqvist, C. \&Konttinen, Y.T. Collagenases in different categories of peri-implant vertical bone loss. Journal of Dental Research. (2000) 79: 1870-1873.

11. Nomura, T., Ishii, A., Shimizu, H., Taguchi, N., Yoshie, H., Kusakari, H. \& Hara, K. Tissue inhibitor of metalloproteinases-1, matrix metalloproteinases-1 and -8 , and collagenase activity levels in peri-implant crevicular fluid after implantation. Clinical Oral Implants Research (2000) 11:430-440.

12. Silness J, Löe H. Periodontal disease in pregnancy II. Correlation between oral hygiene and periodontal condition. Acta odontologica scandinavica 1964:22:121-135

13. Muhleman H, Son S. Gingival sulcus bleeding- a leading symptom in initial gingivitis. Helvetica OdontologicaActa. 1971; 33:107-13.

14. Bauman GR, Mills M, Rapley JW, Hallmon WH. Clinical parameters of evaluation during implant maintenance. Int J Oral Maxillofac Implants 1992;7:220-227.

15. You, T.M., Choi, B.H., Li, J., Xuan, F., Jeong, S.M. \& Jang, S.O. Morphogenesis of the peri- implant mucosa: a comparison between flap and flapless procedures in the canine mandible. Oral Surgery, Oral Medicine, Oral Pathology, Oral Radiology, and Endodontics (2009) 107:66-70.

16. Ahmed Al-Majid, Saeed Alassiri, Nilminie Rathnayake, Taina et al. Matrix Metalloproteinase- 8 as an Inflammatory and Prevention Biomarker in Periodontal and PeriImplant Diseases. Int. J. of Dent (2018) 189:132_ 127.

17. Berglundh, T., Abrahamsson, I., Welander, M., Lang, N.P. \& Lindhe, J. Morphogenesis of the peri-implant mucosa: an experimental study in dogs. Clinical Oral Implants Research (2007) 18:1-8.

18. E. F. de Morais, J. C. Pinheiro, R. B. Leite, P. P. A. Santos, C. A. G. Barboza, and R. A. Freitas, "Matrix metalloproteinase-8 levels in periodontal disease patients: a system- atic review," Journal of Periodontal Research, vol. 53, no. 2, pp. 156-163, 2017

19. Leppilahti JM, Ahonen MM, Hernández M, Munjal S, Netuschil L, Uitto VJ, et al. Oral rinse MMP-8 point-of-care immuno test identifies patients with strong periodontal inflammatory burden. Oral Diseases. 2011;17:115-22.

20. Leppilahti JM, Sorsa T, Kallio MA, Tervahartiala T, Emingil G, Han B, et al. The utility of gingival crevicular fluid matrix metalloproteinase- 8 response patterns in prediction of site-level clinical treatment outcome. J Periodontol. 2015;86:777-87.

21. Giannobile WV. Host-response therapeutics for periodontal diseases. J Periodontol. 2008;79(8 Suppl):1592-600

22. Leppilahti JM, Ahonen MM, Hernández M, Munjal S, Netuschil L, Uitto VJ, et al. Oral rinse MMP-8 point-of-care immuno test identifies patients with strong periodontal inflammatory burden. Oral Diseases. 2011;17:115-22.

23. Kivelä-Rajamäki M, Maisi P, Srinivas R, Tervahartiala $\mathrm{T}$, Teronen $\mathrm{O}$, Husa V, et al. Levels and molecular forms of MMP-7 (matrilysin-1) and MMP-8 (collagenase-2) in diseased human peri-implant sulcular fluid. J Periodontal Res. 2003;38:583-90.

24. Kivelä-Rajamäki MJ, Teronen OP, Maisi P, Husa V, Tervahartiala TI, Pirilä EM, et al. Laminin-5 gamma2-chain and collagenase-2 (MMP-8) in human peri-implant sulcular fluid. Clin Oral Implants Res. 2003;14:158-65.

25. Kiili M, Cox SW, Chen HY, Wahlgren J, Maisi P, Eley $\mathrm{BM}$, et al. Collagenase-2 (MMP-8) and collagenase-3 (MMP-13) in adult periodontitis: molecular forms and levels in gingival crevicular fluid and immune localisation in gingival tissue. J Clin Periodontol. 2002;29:224-32.

26. Mäntylä $P$, Stenman M, Kinane DF, Tikanoja S, Luoto $\mathrm{H}$, Salo T, et al. Gingival crevicular fluid collagenase-2 (MMP-8) test stick for chair-side monitoring of periodontitis. J Periodont Res. 2003;38;436-39.

27. Hanemaaijer R, Sorsa T, Konttinen YT, Ding Y, Sutinen $\mathrm{M}$, Visser H, et al. Matrix metalloproteinase-8 is expressed in rheumatoid synovial fibroblasts and endothelial cells. Regulation by tumour necrosis factor-alpha and doxycycline. J BiolChem. 1997;272:31504-09.

28. Basegmez C, Yalcin S, Yalcin F, Ersanli S, Mijiritsky E. Evaluation of periimplantcrevicular fluid prostaglandin E2 and matrix metalloproteinase- 8 levels from health to periimplant disease status: a prospective study. Implant Dent. 2012;21:306-10. 